\title{
EL INGENIO COMO CATEGORÍA CENTRAL DE HERMENÉUTICA BARROCA DE BALTASAR GRACIÁN Dora Elvira García*
}

Entendimiento sin agudeza ni concepto es sol sin luz, sin rayos...

Baltasar Gracián ${ }^{1}$

\section{A modo de introducción}

El mundo barroco español de la primera mitad del siglo XVII se encuentra inmerso en momentos críticos de la historia de España. ${ }^{2}$ Ante ese mundo cambiante e inestable, en donde todo es fugaz y discordante, surgen escritores que se enfrentan

* Tecnológico de Monterrey, CCM.

${ }^{1}$ Baltasar Gracián, Agudeza y arte de ingenio, 2004, España, Larumbre, clásicos aragoneses, prensas Universitarias de Zaragoza, vol. 1, p. 20.

${ }^{2}$ La bancarrota del reinado de Felipe II genera crisis económicas, pero además de éstas hay también crisis demográfica, social y política. La crisis de la hegemonía católica inicia su ruptura al unísono del reforzamiento de las potencias protestantes del norte de Europa. a esa realidad e intentan implantar orden y claridad en medio de ese desconcierto, ${ }^{3}$ además de convertirse en testigos y relatores de los tiempos de crisis y decadencia que les tocó vivir.

En ese período aparece -entre otros grandes autores- Baltasar Gracián, uno de los más emblemáticos pensadores del espíritu barroco, ${ }^{4}$ con una conciencia profundamente reflexiva que se encarga de atestiguar

${ }^{3}$ Emilio Blanco, "Prólogo", en Baltasar Gracián, Oráculo. Manual y arte de la prudencia, 2000, Madrid, Debate Editorial, p. 18.

${ }^{4} \mathrm{La}$ obra maestra de ese período es el Criticón; pertenece, junto con Calderón, al grupo de escritores barrocos y se ubica dos generaciones después de la de Góngora y una después de la de Quevedo. 
las crisis y los duros tiempos, y procede a sellarlos en sus obras. En ellas utiliza diversos recursos para, en primer lugar, poder publicar cosas que, como jesuita, serían difícilmente aprobables para publicarse, dado que en ellas expresaba sus preocupaciones y vivencias más bien profanas. Gracián experimentó "la natural alternancia barroca entre lo humano y lo divino [que] no podía por menos que manifestarse, a veces, de un modo tenso y contradictorio". 5 Mientras que sus superiores advertían que su ejercicio literario escondía una excesiva ambición mundana, él señalaba que pretendía ser 'un hombre de buena elección'. Esa elección se basaba tanto en valores sociales y políticos, y sobre todo también, en criterios estéticos y morales. Sus preocupaciones sobre la política, el poder, la belleza, la moral y las cuestiones relativas a lo religioso, abarcan todas aquellas facetas que les interesaban a los hombres barrocos. Su preocupación por el ser humano es una constante muy poderosa en su pensamiento, de ahí que sus pretensiones recaigan de manera fundamental en la realización moral que nombrara como señorío.

En este escrito pretendemos hacer algunas reflexiones incipientes en

${ }_{5}^{5}$ Javier García Gubert, Baltasar Gracián, 2002, Madrid, Síntesis Editores, p. 11. torno a la hermenéutica barroca de Baltasar Gracián y para ello se rescatan algunas categorías que son centrales en su pensamiento; entre ellas mencionamos de manera principal al ingenio.

\section{Las claves hermenéuticas gracianas: ingenio, ${ }^{6}$ fantasía e invención}

La constructio humanista barroca expresada por Gracián, utiliza algunos recursos característicos del humanismo barroco de ese momento. Uno de ellos es la categoría del ingenio, ${ }^{7}$ que rompe con las formas restrictivas del conocimiento que le precedieron, expresadas mediante reglas que ciñen y restringen, heredadas del aristotelismo y del tomismo duros. Con este nuevo proceder, lo

\footnotetext{
${ }^{6} \mathrm{El}$ ingenio había sido en épocas pasadas una facultad indefinida; en la época de Gracián adquiere autonomía y un lugar central por parte de los escritores, los cuales resaltaban en sus composiciones la originalidad, la variedad y la novedad. En la Ratio studiorum (1586 elaborada por los jesuitas) el desarrollo del ingenio tenía una intención intelectual y moral más que estilística. La invención actuaba de estimulante de la razón discursiva encaminándola a una inteligencia práctico social. Cfr. Jorge M. Ayala, "Introducción”, en Baltasar Gracián, Agudeza y arte de ingenio, p. XLI.

${ }^{7}$ La palabra ingenio en las lenguas romances significó lo mismo que en el latín: talento natural; don que hace sobresalir a las personas que poseen en abundancia. El ingenio no es una facultad distinta del entendimiento.
} 
que el filósofo aragonés busca es la originalidad, la variedad y la novedad. El ingenio es un recurso de la inteligencia razonadora que propicia un mayor sentido de la invención y se convierte en un estímulo de la razón discursiva orientada hacia una inteligencia práctico-social.

El elemento en el que se apoya tal recurso del ingenio es la palabra, que es fundamental en el pensamiento graciano. Las personas razonamos con palabras y mediante su uso nos vamos humanizando. El ideal moral graciano se encarna en la palabra porque por ella se refleja -en los pensamientos- la integridad de la vida, la justicia y la sabiduría. De este modo, el dominio de la palabra implica el dominio de las facultades preeminentes del hombre como ser racional. Entonces, la relevancia de la retórica radica en que significaba la culminación de la formación humanística para el desarrollo de las facultades intelectuales.

Gracián pretendió crear un arte que implicaba un estilo de ser y de pensar cuyo fundamento es el ingenio, y cuyo objeto es la agudeza ${ }^{8}$ y sus

${ }^{8}$ La agudeza no es una retórica pero está dentro de la corriente retórica aristotélica, base de la educación jesuítica gracias a la progresiva implantación del libro del P. Cipriano Suárez De Arte Rethorica libri tres ex Aristotele, Cicerone et Quintiliano praecipue deprompti (Coimbra, 1561; Venecia, 1565). Esta obra estaba dividida en tres partes: invención, disposición y elocución y su conceptos. Es cierto que ese proceder podría conducir a la desrrealización de la realidad, creando con ello un mundo ficticio sustentado en palabras. Sin embargo, con ello también se daba lugar al desvelamiento de nuevas verdades que eran limitadas a la comprensión deductivo-racional. Gracián es un artífice de esta forma de proceder que resulta típica del pensamiento y la literatura del barroco. La realidad está por descubrirse y por ello incide ahí el ingenio, al intentar descifrar y crear. En aras de no repetir lo ya hecho, los autores barrocos buscaron la novedad. Con esto intentaban romper con los modelos de imitación de los clásicos y procuraban ser ingeniosos, creando nuevas formas y produciendo un nuevo arte. De ahí que los racionalistas del siglo XVIII abjuraran de este movimiento barroco considerándolo como caótico, bárbaro y sin rigor en absoluto. Debido a la amplitud de

doctrina procedía principalmente de Aristóteles, Cicerón y Quintiliano. Cfr. Jorge M. Ayala, "Introducción”, en Baltasar Gracián, Agudeza y arte de ingenio, $\mathrm{p}$. XXVI. Retórica y poética van siempre unidas en la pedagogía jesuítica pues mediante la ratio studiorum integra oratoria y poética. La ratio es un manual de la formación intelectual y religiosa de los alumnos de los jesuitas. Equivale a un ordo $o$ ars que se inspira en el humanismo del norte de Europa a comienzos del siglo XVI (Erasmo, Vives, Budé). La ratio recomendaba el libro III de la retórica aristotélica que se dedica a la elocución. La palabra agudeza, del verbo acuo, significa aguzar, afilar, sacar punta. Así, agudeza es sinónimo de sutileza, sagacidad, penetración, argucia. 
expresiones que se aludían como barrocas se propició que tal movimiento epocal dejara de tener un significado preciso.

Como decíamos, el barroco muestra una pasión por la originalidad; los autores no querían más ser imitadores, sino que sus pretensiones se inclinaban a ser como lo habían sido los clásicos. Así, Gracián observó que "son tenidos por imitadores de los pasados los que les siguen; y por más que suden, no pueden purgar la presunción de imitación". 9 Adquirir originalidad no resultaba fácil y por ello Gracián defendía que "más se requiere hoy para un sabio que antiguamente para siete". ${ }^{10}$ En todo esto, es posible señalar con Gracián que si no podemos ir más allá de las ideas, al menos las debemos de renovar, como lo afirma en las siguientes líneas: "aunque las cosas sean muy sabidas, si el modo de decirlas en el retórico, y del escribirlas en el historiador fuere nuevo, las hace apetecibles". ${ }^{11}$

Para lograr esa originalidad buscada, era necesario echar mano de algunos recursos propuestos por los autores del barroco que emanaban del ingenio. Los tratados que surgieron en esa época -no sólo en España

${ }^{9}$ Gracián, El Discreto, El Criticón, El Héroe, 1977, México, Porrúa, Sepan Cuántos.

${ }^{10}$ Gracián, Oráculo, op . cit., Aforismo 1.

${ }^{11}$ Gracián, Discreto, op. cit., Realce 22. sino también en Italia- intentaron explicar esa nueva modalidad. Así, el ingenio -como práctica del discurso intelectual e ingenioso- fue la que interesó a Gracián; interés que Giambattista Vico, un siglo más tarde, expresó al apuntar que los italianos están dotados con un lenguaje que constantemente evoca imágenes. ${ }^{12}$

El estudio del ingenio en el ambiente cultural de Gracián no era algo extraño. En ese contexto barroco surgen tratados teóricos que investigaban acerca de tal categoría. Muchos jesuitas, al igual que nuestro filósofo aragonés, se interesaron por esta categoría en esos años que corrían $(1640)^{13}$ y su utilización fue algo muy específico de la época del barroco. Los tratados de esa época resultan muy significativos y dan cuenta del descubrimiento, en tales escritos, de dicha categoría. Este recurso ha sido la piedra de toque del intelectualis1,95 .

${ }^{12} \mathrm{Cfr}$. G. Vico, De studiorum ratione, Opere

${ }^{13}$ Ejemplos que se pueden mencionar son Matteo Matero Pellegrini que publicó Della Acutezze, 1639, texto que analizaba los géneros de los ingenios y más adelante, en 1650, I fonti dell'ingegno, un texto que analizaba el rol y los métodos de la ingenuidad de la mente en la invención de todos tipos de discurso. Por su parte Pietro C. Sforza Pallavicino publicó el Tratado dello stile e del dialogo en 1646 que daba reglas al uso del ingenio en su empresa. Emmanuel Tesauro escribió Il cannonchiale aristotlélico en 1654 que teoriza extensa y sistemáticamente sobre todas las formas del ingenio, enfatizando el uso del ingenio en modas literarias barrocas. 
mo barroco que se expresó como el ejercicio del ingenio de la mente para develar las similitudes inesperadas, las relaciones, las analogías o las correspondencias entre ideas, imágenes o inusuales dimensiones de la realidad.

Podríamos decir que una de las preocupaciones fundamentales de Gracián se ubicó en esclarecer y dar un método al ingenio generado en la mente, inquietud presentada sobre todo en su Agudeza y arte de ingenio. El punto de partida es un realismo que parte de la simple aprehensión de las ideas en su consecuente relación con los juicios y el discernimiento. Precisamente por la vaguedad de nuestra percepción de la realidad, en donde no se hacen distinciones, se necesita de un procedimiento que clarifique las generalidades en los particulares bien definidos. Para Gracián es preciso un método de discernimiento y lo encuentra en el ingenio, ya que éste muestra las operaciones básicas para la percepción de los detalles. El texto Agudeza provee una característica de arte a la práctica del ingenio de la mente, una práctica que según Gracián en Agudeza y arte de ingenio era antes huérfana de cualquier teoría. ${ }^{14} Y$ que se creaba mediante la fantasía.

${ }^{14}$ Gracián, Agudeza y Arte de Ingenio, "Al Lector" y Discurso I, p. 11 y 15-20. La agudeza tomada como sinónimo de ingenio es la categoría
La relación de la teoría del ingenio con la retórica replanteada en el siglo XVII y característica del barroco, daba cuenta del intento de proveer un método a la invención, otro recurso graciano. Es interesante apreciar cómo las teorías sobre el ingenio generalmente ubicaban a la invención fuera del radio de lo racional, mientras que para Gracián el ingenio tenía un componente racional. ${ }^{15}$

Gracián, a diferencia de otros colegas como Pellegrini, Pallavicino y Tesauro, no explicitaba -en su Agudeza y arte de ingenio- referencia alguna a los retóricos clásicos quizá para enfatizar su originalidad teórica aunque su gran erudición hace constantemente citar a los clásicos, principalmente para ilustrar sus propias teorías sobre cuestiones del ingenio.

Las definiciones de Gracián presentan al ingenio como un acto de entendimiento que no es ni el juicio ni la inferencia, sino una nueva conceptualización referida a la guía de la mente, a la conceptualización de una idea por primera vez. En un primer momento significó precisamente la introducción de nuevas ideas en

suprema de la antropología graciana. Cfr. Jorge M. Ayala, "Introducción”, en Baltasar Gracián, Agudeza y arte de ingenio, p. LIV.

${ }^{15}$ Como en Aristóteles, Quintiliano, Pellegrini, Tesauro y Vico. 
la mente y no la representación de un pensamiento preexistente en la mente. Así, y como ya lo decíamos, la conceptualización era un acto de entendimiento, un concepto se presenta a la mente por primera vez y con ello produce el ingenio. ${ }^{16}$ En la Agudeza afirma que "fácil es adelantar lo comenzado; arduo el inventar [...]Hallaron los antiguos métodos al silogismo [...] sellaron la agudeza" ${ }^{17}$ Con esto es posible apreciar que la lógica y el arte del silogismo son insuficientes para la adquisición de un nuevo aprendizaje que, en cambio sí es logrado por el ingenio, proceso que abstrae ideas de los datos crudos. En este sentido, es el proceso racional básico que emana de la experiencia sensible y de los estímulos imaginativos de pensamientos abstractos.

El texto de la Agudeza (1642) estudia el ingenio que es necesario para que tanto el político como el

\footnotetext{
${ }^{16}$ Desde el punto de visa analítico la diferencia entre ingenio, agudeza y concepto es que el ingenio es la dimensión superior del entendimiento humano y se caracteriza por la sutileza del pensar. La fuerza del ingenio para crear relaciones y establecer correspondencias, para engendrar conceptos, es la agudeza. El concepto se define como el pensamiento formado con tales relaciones y correspondencias. Así la agudeza es el poder de penetración del ingenio y se diversifica en agudeza de pensamiento o concepto, de palabra o verbal y de acción. Así, el concepto es una clase de agudeza. Cfr. Jorge M. Ayala, “Introducción”, en Baltasar Gracián, Agudeza y arte de ingenio, p. LXX.

${ }^{17}$ Agudeza, Discurso 1, p. 11.
}

héroe ${ }^{18}$ logren sus cometidos llevando al ingenio al nivel del arte. Este tratado lo dedica al ingenio y el reino teórico de este ingenio se encuentra en los métodos para el descubrimiento o producción, ${ }^{19} \mathrm{El}$ arte de establecer correspondencias contiene el arte del ingenio, como lo señala en el segundo Discurso del texto de la Agudeza cuando dice "que esta correspondencia es genérica [...] y abraza todo el artificio del ingenio". ${ }^{20}$

Los elementos retóricos constituyen los elementos instrumentales para el ingenio; por ello Gracián señala "válense la agudeza de los tropos y figuras retóricas, como de instrumentos para exprimir cultamente sus conceptos, pero contiénense ellos a la raya de fundamentos materiales de la sutileza, y cuando más, de adornos de pensamiento". ${ }^{21} \mathrm{Al}$ profundizar en el texto de la Agudeza se pueden apreciar su recurrencia a los tópicos, tropos y figuras retóricas, a los argumentos retóricos y al estilo de los discursos por la relación que tienen con el ingenio. Por ejemplo, algunos de los Discursos de la $\mathrm{Agu}$ deza los dedica a los ingenios, ${ }^{22}$ otros

${ }^{18}$ Los perfiles del político y del héroe fueron trabajados, respectivamente en El Político, op. cit., y en El Héroe, op. cit.

${ }^{19}$ Gracián, Agudeza, Discurso 2.

${ }^{20}$ Idem.

${ }^{21}$ Gracián, Agudeza, “Al lector”.

${ }^{22}$ Gracián, Agudeza, 9 al 123 se dedican a los ingenios. 
discursos se relacionan con la similitud ${ }^{23}$ los cuales están dedicados a los ingenios por medio de la hipérbole. Otros más ${ }^{24}$ dedicados a los ingenios que producen argumentos retóricos. Si no significa que estos métodos son parte del arte del ingenio, al menos quiere decir que ellos son instrumentos que contribuyen al ejercicio del ingenio.

El tratado de la Agudeza y arte del ingenio es uno de la invención y pretende explicar y dar un poder artístico a la inventiva de la mente. Asimismo, señala que las teorías del ingenio pueden darnos explicaciones, así como el arte que tiene que ver con las maneras como el entendimiento humano aprehende o produce conceptos. Al establecer correspondencias entre cosas aparentemente no asociadas, la mente emerge desde meras experiencias a las ideas abstractas. Con ello muestra que las técnicas del ingenio y las técnicas de conceptualización son generalmente las mismas, en tanto tienen el mismo resultado de generar nuevas ideas. El arte de la conceptualización debe servir a ser un método de invención como el descubrimiento de la creación de ideas. La invención de ideas da lugar a la invención de argumentos e inferencias, dado que las ideas

\footnotetext{
${ }^{23}$ Gracián, Agudeza, Discursos 19 al 22.
}

${ }^{24}$ Gracián, Agudeza, Discursos 36 al 38. preceden a estos últimos y que tales ideas son precedentes de juicios $\mathrm{y}$ de acciones. ${ }^{25}$

De este modo, el arte del ingenio de Gracián se relaciona frecuentemente con la argumentación y se utiliza en los discursos. Se relaciona con los términos del silogismo o entre proposiciones en un entimema, ${ }^{26}$ aunque, como ya decíamos antes, distingue el ingenio de la lógica.

Ahora bien, la importancia que tiene el ingenio en el marco teórico del pensamiento graciano tiene repercusiones dentro de sus preocupaciones políticas y morales. La preocupación por la filosofía moral es fundamental para Gracián porque pretende reorientar el mundo que está 'al revés'. La manera como lo hace, es promoviendo un nuevo paradigma de persona (el héroe o el político, por ejemplo). Gracián pretende así la forja de un nuevo tipo de hombre cuyo horizonte práctico es lo político, pero que ha de fundarse en la prudencia. ${ }^{27}$ Por ello, el pensamiento graciano es una fenomenología antropológica que se proyecta en la praxis por medio de una escatología bíblico-cristiana, que era el punto de partida de los jesuitas para erradicar el mal en el mundo. De ahí que su

${ }^{25}$ Agudeza, Discursos 2.

${ }^{26}$ Gracián, Agudeza, Discursos 3, 36 y 38.

${ }^{27}$ La prudencia es a la vida moral lo que es el ingenio para la intelectual. 
teoría se convierta en una explicación de ese ingenio en tanto virtud y facultad, que forma el carácter de los políticos y hombres persuasivos. ${ }^{28}$ Lo que hace Gracián es un método de ubicar los aspectos contingentes de los asuntos humanos, alcanzando soluciones sobre cuestiones prácticas por medio del discurso, como lo muestra en sus diferentes obras. ${ }^{29}$

Las comparaciones en los casos extremos llevan a la razón a apreciar similitudes entre diferentes asuntos generando así claridad en los objetos del entendimiento. Así, el ingenio logra capturar - a partir de las ideas que son abstractas y universales- la unicidad de los casos contingentes. La comparación es heurística, en tanto el arte de hallar en dónde las relaciones y las señales o recuerdos son compartidos por los objetos abstraídos y percibidos por la mente. Estas comparaciones por semejanza se pueden apreciar en las metáforas y en otras formas del lenguaje figurativo, en los ejemplos y en las analogías que surgen a partir de la aprehensión de ideas, y desde ahí se descubre la posible argumentación.

En todas estas ejemplificaciones sobre las categorías gracianas, podemos apreciar la preocupación por

${ }^{28}$ El Héroe, Primor 3 y el Discreto, realce 1.

${ }^{29}$ Oráculo, aforismo 80, 136, 222 y 227; Discreto 7; Héroe 6 a 11; Oráculo, af. 250 y 294; Discreto 19 y Agudeza, Discursos 39 al 47. interpretar el mundo, por entenderlo de una manera más íntegra y más completa y con una orientación a pensar en un mundo mejor.

\section{La casuística y la prudencia: el señorio}

No es posible adentrarnos en el pensamiento de Gracián sin apreciar su contexto y concretamente su pertenencia a la Compañía de Jesús. Su entorno lo influye en sus reflexiones pero recae de manera fundamental en lo moral. En el contexto histórico de ese momento los jesuitas se mostraban laxos y Gracián no era un excepción, sino muy al contrario. Frente a sus tareas de confesor y consejero de almas -en donde se le presentaban casos muy problemáticos y complejos-Gracián siempre se mostró con un espíritu más abierto que sus compañeros de Orden sobre los angostos límites del 'rigorismo'; con ello pretendía un entendimiento más abierto y tolerante.

Las teorías del ingenio de Gracián no eran únicamente aplicadas al lenguaje ingenioso, sino que tenían que ver con la proposición de reglas a la mente perspicaz que parte de una casuística, en relación con el discernimiento de casos concretos. Con esto, se introducía la presencia de la prudencia que tensaba los polos 
-por un lado- de la teología con sus propuestas generales y universales y, - por el otro- la casuística, que emanaba de los casos concretos que se le presentaban en las labores propias de su investidura. De ahí que esta tensión confronte matices morales que retan al ingenio de la mente. En las actividades de oratoria y específicamente de las predicaciones o sermones, se adoptaron algunas de las modas literarias del momento, tales como estilos complejos, ideas sutiles e interpretaciones ingeniosas. De ahí que aparecieran gran cantidad de escritos sobre estos temas como sermonarios y florilegios que proporcionaban algunas técnicas de amplificación para sermones, que a veces se publicaban y que utilizaban las comparaciones y contrastes con su respectiva revisión de las circunstancias y similitudes. Esta técnica de comparaciones y contrastes fue un precedente directo de ciertas teorías del ingenio, como lo podemos apreciar en Gracián, cuando las ubica explicando algunos de sus conceptos, como comparaciones. ${ }^{30}$ Éstas aprecian las circunstancias compartidas o diferentes de aquellas cosas compartidas, las similitudes, la relevancia de las ponderaciones y la sutileza. Este proceder lo explora también en el Oráculo, en donde

\footnotetext{
${ }^{30}$ Gracián, Agudeza, Discurso 4.
}

especifica algunas reglas acerca de la acción moral concreta, al proponer máximas prudenciales. Tales máximas son abiertas a diversas aplicaciones y casos contingentes. Se presentan máximas que llaman la atención a las trampas morales de diversas situaciones personales, de índoles diversas, ya morales, sociales o culturales. Ellas especifican tácticas o estrategias de conducta, son máximas que asientan guías morales y religiosas, establecidas desde la tradición, articuladas con la sabiduría popular revalorada y realzada por Gracián. La frase que dice "¿de qué sirve el saber si no es práctico?" del Discreto $^{31}$ muestra la preocupación fundamental de nuestro pensador por hacer recaer las acciones en 10 práctico, en la vida.

Y si su idea versaba fundamentalmente sobre la reivindicación humana, entonces sus pretensiones morales recaían -y era una exigencia explícita- en la educación. En ese sentido, mostraba -al igual que sus contemporáneos- la fuerte herencia aristotélico-ciceroniana que hacía uso de la retórica, y que enfatizaba el papel de la invención, el uso de las emociones en la persuasión y el recurso del ornamento en el estilo. Los tópicos y otras fuentes de invención

\footnotetext{
${ }^{31}$ Gracián, Discreto. 232. Además, y siguiendo los postulados ignacianos, la acción no puede separarse de la contemplación.
} 
servían para enseñar composición, como sería la creación de emblemas, para enseñar, por ejemplo, argumentación. Mediante la lectura de la Retórica de Aristóteles, ${ }^{32}$ y especialmente la teoría de la metáfora, los jesuitas fusionaron la invención y el estilo. Expresión clara de esta fusión se encuentra en las teorías del ingenio. Pero la presencia de la retórica era fundamentalmente motivadora y procuraba mover la voluntad de las almas desmotivadas y mostrarles un bien deseable definido por la razón por medio de un estilo poderoso $\mathrm{y}$ las técnicas de amplificación. Así se conjuntaba con el componente racional de la teoría de las emociones. El proceder seguía una secuencia: primero se proponía un bien utilizado para la motivación de la audiencia, éste se analizaba y se amplificaba mediante los tópicos de la invención, y después se probaba de manera argumentativa.

Es importante señalar que el ambiente en el que estas reflexiones se desarrollaban era específicamente escolástico y no se separaba por completo -como los modernos 10 hicieron más adelante- la psique en dos unidades: entendimiento y voluntad. Así, había una razón humana que entendía la verdad y deseaba el bien.

\footnotetext{
${ }^{32}$ Cfr. Aristóteles, Retórica, tercer libro.
}

Precisamente uno de los problemas de Gracián fue el papel de la razón en la persuasión de la voluntad. Con ello, la cuestión de mover las almas hacia la virtud y el alejamiento del vicio pertenecía a la oratoria moral. Su preocupación era mover las almas a acciones concretas, de modo que los predicadores debían expandir sus recursos para fortalecer el argumento retórico (esto es, el juicio) ${ }^{33}$ en aras de una mejora moral.

De este modo y con lo ya dicho, en el interés de la educación surgieron, además de la retórica, las teorías del ingenio. La lógica escolástica, la psicología y la metafísica proporcionaron bases teóricas de los tratados del ingenio. La fundamentación del juicio prudencial sobre el ingenio y las experiencias aprendidas del tomismo muestran el antecedente que subyace a estas teorías del ingenio. Con esto, la recomendación de la práctica del ingenio preservaba tanto la tradición humanista como las tradiciones del pensamiento europeo que promovían la erudición. Además de ubicarse en el terreno de las ideas, el ingenio se extendió a campos que eran fuertemente simbólicos. De ahí la relevancia de la emblemática -ya mencionada- como expresión del lenguaje simbólico, y éste a su vez como muestra del ingenio y cuya

\footnotetext{
${ }^{33}$ Gracián, Agudeza, Discurso 4.
} 
orientación era fundamentalmente pedagógica.

Los elementos culturales incorporaban un fuerte elemento del lenguaje, defendido en Italia y en España durante la época del ingenio, y que más adelante fue nostálgicamente extrañado por uno de los últimos humanistas: Giambattista Vico, cuando los renegados de la Modernidad pretendían acabar con ese lenguaje simbólico, que era expresión del ingenio.

Entonces, desde las categorías del ingenio, la fantasía, la invención y la imaginación, Gracián pasa a las cuestiones morales, cuestiones en las que, al fin y al cabo descansarán sus preocupaciones por lo humano. El paso a lo moral no es fortuito dada la vocación espiritual del filósofo aragonés quien insiste en el poderío moral que generan las personas al ejercitar a plenitud sus poderes morales. Su preocupación por la moralidad intentaba proporcionar un arte para el desarrollo de las facultades más altas en aras del logro de la excelencia de las personas en un ambiente moral. ${ }^{34}$

El carácter moral de las personas y su felicidad potencial radica en lo que Gracián nombra como el señorío, que se basa en lo que significa ser maestro en los hábitos de la razón y

\footnotetext{
${ }^{34}$ Gracián, El héroe, “Al Lector”.
}

entre ellos, el del ingenio, que funge como categoría central. La teoría que Gracián presenta sobre el señorío subyace a toda su filosofía y captura el sentido del ingenio en la persona cuidadosa, en el político y en el discreto, es decir, en quien es el maestro. ${ }^{35} \mathrm{El}$ maestro poseía los hábitos del ingenio, quien para pensadores clásicos como Aristóteles y Cicerón, era la persona que tenía 'razón práctica', era aquel que podía deliberar bien sobre lo que era bueno para él, es decir, el hombre virtuoso. Gracián tenía un especial interés en quienes hacían las actividades más que en las actividades mismas. Por ejemplo, en sus libros hablaba del Héroe, del caballero Discreto o del Político, y en la Agudeza se refiere a nuestra mente en cuanto ingeniosa. El señorío incluye el poder comprehensivo del entendimiento que contiene el ingenio, la prudencia, el juicio, la predilección, la elección y la voluntad como fuerza que guía a acciones fructíferas. Además, a partir de los marcos de las circunstancias manejadas propiamente, es posible perfeccionar los poderes morales de una persona y finalmente es posible el alcance de la virtud. Mediante

${ }^{35}$ El héroe fue la llave para el entendimiento de su sistema de ideas, una obra publicada en su madurez (1637). Esta obra presenta de manera bastante sistemática los principales conceptos que reaparecen en sus obras posteriores: el concepto de señorio de una persona en su vida moral. 
este proceder, se logra la actualización de todas las potencialidades de una persona a través de su vida. Por ello, la relevancia del Oráculo se ubica en los aforismos que se refieren a la idea de llegar a ser una persona completa, que discierne y que es un modelo de prudencia, discreción y heroísmo, y así se es señor de sí mismo. Éste es el 'maestro', el hombre virtuoso que por sus buenos hábitos de pensamiento y de vida posee la sabiduría práctica. El ethos con el que se reviste este hombre y la virtud son los elementos que definen su excelencia, como lo señala en uno de sus aforismos: "la verdadera soberanía consiste en la entereza de costumbres". ${ }^{36}$

Ese señorío lo poseen muy pocos, en sus palabras dice: "brilla en algunos un señorío innato, una secreta fuerza de imperio que se hace obedecer sin exterioridad de preceptos, sin arte de persuasión [...] Reconocen al león las demás fieras, en presagio de naturaleza y, sin haberle examinado el valor le previenen zalemas". ${ }^{37}$ Este don es el genio y parece incluir ciertas connotaciones monárquicas y aristocráticas del concepto de señorío a las que Gracián explícitamente alude. En el Politico hace referencia al rey Fernando de Aragón que pertenecía a la raza monárquica heroica, en la que parecen heredarse tanto la prosapia como las propiedades naturales, morales, así como los privilegios y los achaques de la naturaleza y la fortuna. Sin embargo, al discutir lo que es el señorio, no lo reducía únicamente a la nobleza de los reyes de nacimiento, sino que lo extendía a todo tipo de actividades humanas de cualquier persona, siempre y cuando esas personas poseyeran cierta autoridad y autonomía al tomar decisiones, y cuyo soporte se basa en la razón y la virtud. ${ }^{38}$ Ahí se muestran la libertad, la autoridad, la competencia, el despejo (primero se es señor de sí y luego de todo) y la responsabilidad.

El lugar superior del señorio puede ser apreciado gracias a lo que es el ethos del maestro, que es más importante que el logos: el ethos asimila al logos y lo hace significativo y plausible. El ingenio implica lo que es el buen sentido de una persona virtuosa, de ahí que las buenas razones, la buena toma de decisiones y los buenos logros no tienen relevancia sin las personas virtuosas.

$\mathrm{Al}$ no ser única la categoría del señorío o el genio, es posible aceptar que hay diversidad en ese señorío o genio y que esta diversidad es la ocasión para el argumento y el disrismo 103.
${ }^{38}$ Como sucede en Gracián, Oráculo, afo-
${ }^{36}$ Gracián, Oráculo, Aforismo 103.

${ }^{37}$ Gracián, Héroe, Primor XIV. 
curso público. ${ }^{39}$ La gente es diferente en genio, talentos, preferencias y en áreas tales como la fortuna y las oportunidades económicas y sociales, por ello es necesaria la retórica. De ahí la riqueza de la humanidad en la que además de las diferencias hay también ámbitos comunes de señorío $\mathrm{y}$ de virtud (tales como el entendimiento ${ }^{40}$ y la voluntad). Esas bases comunes han de ser compartidos por todas las personas. ${ }^{41}$

Desde la perspectiva graciana, el poder del ingenio es el que congrega, dado que es un poder que descubre las potencialeidades ocultas de las personas que conjunta a las sociedades. Es un poder que congrega por medio de asociaciones a la dispersada humanidad y es el que guía a las personas a los niveles de sofisticación más elevados de civilización. ${ }^{42}$

${ }^{39}$ Gracián, Oráculo, Aforismo 294.

${ }^{40} \mathrm{El}$ entendimiento como poder humano amplio comprende funciones compartidas tales como el ingenio y el juicio. El ingenio se refiere al discernimiento en un sentido más reducido. Se refiere también al poder de conceptualización en tanto la aprehensión de ideas desde la realidad, o como la producción de la mente o la invención de nuevas ideas. Un ingenio prominente se caracteriza por fuerte vigor, prontitud y gentileza.

${ }^{41}$ Gracián, Discreto, Realce 8.

${ }^{42} \mathrm{El}$ concepto del ingenio es el que le permitió a Vico reconciliar el desarrollo de las diversas civilizaciones con su conciencia de la ley natural y eterna. Al descubrir los potenciales naturales de las sociedades, el ingenio gradualmente guía a las personas a diferentes niveles de actualización de sus potencialidades, a diversos niveles y varias civilizaciones de diferentes grados completaban la base de la ley eterna y natural.
El ingenio logra guiar a la gente desde el aislamiento salvaje a las sociedades civilizadas, de 'no ser', 'a ser', y también transforma a los seres humanos de monos desnudos a ser portadores de cultura y tecnología. ${ }^{43}$ Y no sólo crea la cultura y la tecnología para satisfacer las necesidades físicas, sociales y espirituales de las personas, sino que el ingenio también descubre estas necesidades y establece la relación de ellas con la creación de remedios culturales o tecnológicos. Y aún más, el ingenio puede hacer de la cultura y la tecnología símbolos del entendimiento social para adoptar descubrimientos adicionales, creación de artefactos y a alcanzar un aprendizaje por medio del marco común de las personas sobre la realidad. ${ }^{44}$

Para terminar estas reflexiones, podemos señalar que, como puede apreciarse en los diversos temas tratados por Gracián, el camino por recorrer es largo y conforme se va caminando se van abriendo nuevos

${ }^{43}$ Parece que la teoría viquiana sobre el desarrollo de las naciones fue precedida por El Criticón, en donde se hace una análisis del desarrollo de diferentes naciones en términos de niñez cultural, adultez y la edad de la vieja sabiduría.

${ }^{44}$ Gracián clasificó las invenciones en artefactos prácticos que ayudan a la gente a satisfacer una necesidad, y simbólicas que son formas de lenguaje creadas para dar poder a la mente humana con instrumentos adicionales para el entendimiento. Cfr. Gracián, Agudeza, Discurso 47. 
cauces que son cada uno de ellos objeto de estudios específicos en el marco de diversas temáticas filosóficas, epistemológicas, éticas y culturales. ${ }^{45}$ Lo que pretendimos exponer aquí, como puede apreciarse, fue la relevancia de algunas categorías hermenéuticas tales como el ingenio en el marco general del pensamiento graciano, que finalmente está abocada a las expectativas éticas de la humanidad.

${ }^{45}$ El pensamiento graciano postula elementos que defienden el pluralismo en la hermenéutica barroca. Este pluralismo tiene como telón de fondo a las categorías del ingenio, la imaginación y la invención, y se aboca necesariamente a las expectativas éticas de la humanidad. Cfr. Baltasar Gracián, Agudeza y Arte de Ingenio, Discurso III; ahí señala Gracián que 'la uniformidad limita, la variedad, dilata'. 